\title{
O MEDO DO PRAZER E SUA RELAÇÃO COM O RETORNO AO SILENCIAMENTO: UM RELATO DE EXPERIÊNCIA
}

Marcia Jacob Vieczorek ${ }^{\mathrm{i}}$

\begin{abstract}
Resumo: Este relato se propõe a refletir sobre o olhar conservador e o medo de dar voz aos alunos na realização de propostas pedagógicas diferenciadas, retirarando do debate educacional questões emergentes na esfera social e cultural da vivência de nossos educandos, desqualificando debates que possam contribuir para a compreensão e reflexão crítica a respeito da realidade vivida, silenciando vozes, reproduzindo valores e preconceitos baseados em concepções morais e religiosas. Sendo assim, este texto terá como recorte o relato de uma situação que envolveram um projeto com música no Ensino Fundamental em duas escolas, uma pública e uma escola privada.
\end{abstract}

Palavras chave: Educação. Escola. Criticidade.

\section{THE FEAR OF PLEASURE AND THEIR RELATIONSHIP TO RETURN TO SILENCE: AN EXPERIENCE REPORT}

\begin{abstract}
This report proposes to reflect on the conservative gaze and the fear of giving voice to the students in the realization of differentiated pedagogical proposals, removing from the educational debate emergent issues in the social and cultural sphere of the experience of our students, disqualifying debates that can contribute to the understanding and critical reflection on the reality lived, silencing voices and reproducing values and prejudices based on moral and religious conceptions. Thus, this text will have as a clipping the story of a situation that involved a project with music in Elementary School in two schools, a public and a private school.
\end{abstract}

Keywords: Education. School. Criticity.

\section{Introdução}

Desde antes da minha formação acadêmica, que foi realizada na UERJ, campus Maracanã, iniciando a minha vivência como educacadora através de movimentos sociais, aprendi a conceber a Educação enquanto troca para uma construção, seja em sua dimensão social, ideológica, ética, formativa, acadêmica ou política. Sendo assim, atividades voluntárias e colaborativas sempre fizeram parte da minha prática pedagógica como uma atuação cidadã, me distanciando ao máximo da ocupação caridosa/filantrópica, atuando de forma comprometida, seja através de elaboração de projetos, realização de oficinas, dinâmicas, troca de experiências ou grupos de ação, sempre voltada para a democratização de 
acesso, desconstrução das intolerâncias, respeito, direito e conquistas pelas minorias. Algo que pudesse ser recriado e ampliado nas experiências cotidianas.

Elaborar propostas educacionais de intervenção na realidade é um trabalho de compromisso com o outro. Sempre visei a transformação dos sujeitos com os quais interajo, possibilitando a eles a oportunidade de refletir sobre determinadas questões que incomodem e até sobre aquelas que ainda não foram percebidas e, assim, possibilitar que busquem alternativas de ações que possam interferir no mundo enquanto cidadãos críticos e conscientes. Portanto, auxiliando na modificação do estigma de destino préconcebido, que muitas vezes está presente na sociedade com relação às pessoas das classes populares e que acaba influenciando na identificação delas próprias.

$\mathrm{O}$ estudo dos processos de formação das identidades dos alunos que sofrem e praticam procedimentos de exclusão se tornou importante neste trabalho, pois, em geral, o indivíduo excluído sente-se discriminado e estigmatizado, o que acaba por interferir na identificação de si próprio. Nos processos de constituição identitária o reconhecimento do outro é um fator importante: o modo como somos reconhecidos também nos ajuda a saber quem somos (HABERMAS, 1984; MANGUEL, 2008). Se o reconhecimento do outro passa por um processo de discriminação e estigmatização, isso interfere nos processos de formação identitária, podendo levar o sujeito a se sentir humilhado e desumanizado. Não posso afirmar que esse sentimento se desenvolve em todas as alunas e alunos excluídos, porém, de certa maneira, influencia nas diversas formas de participação e legitimação social e individual que esses sujeitos vivenciam. (SEPULVEDA, 2012, p. 18-19).

Ao longo desses anos, em determinadas instituições escolares onde atuei, algumas resistências foram quebradas na medida em que o medo de perder o poder foi substituído pela possibilidade de um trabalho em conjunto, reconhecendo as propostas apresentadas por mim como instrumento importante para a reflexão, tranformação e inclusão. Muitas vezes foi desafiador, mas nunca desmotivador, qualquer trabalho de militância é sempre um trabalho de enfrentamento. Discutir questões sociais, culturais, educacionais e seus desdobramentos com os alunos é um ato político de formação de identidades e cidadania, fazendo do ambiente escolar um lugar também de encontro entre pessoas, de fazer amizades, compreender e enfrentar seus medos, compartilhar ideias, sentimentos, transformar e reinventar a realidade para além dos muros da escola, entendendo que aprender sobre o mundo é se instrumentalizar para agir sobre ele. Conforme FREIRE (2000, p. 63) a tarefa progressista é assim, estimular e possibilitar, nas circunstâncias mais diferentes, a capacidade de intervenção no mundo, jamais o seu contràrio, o cruzamento de braços em face aos desafios. Aprender em parceria faz parte do processo democrático, e como tal, é uma construção.

Talvez ainda estejamos engatinhando no aprendizado e vivência sobre a democracia, mas não podemos desistir e retroceder a um tempo e espaço que não existem mais, que não se encaixam mais nas necessidades da sociedade. Aprendemos a falar e a dar voz, não queremos de volta uma educação que nos cale dentro de uma escola que não nos enxerga. 


\title{
Algumas exposições sobre a educação no momento atual
}

Pensar na Educação hoje, acontecendo como uma ferramenta de modelação do sujeito, nos faz pensar nas implicações para a educação brasileira, no que já foi possível conquistar em termos de contribuir para a formação de um cidadão mais ativo no mundo e no quanto o retorno às práticas mais conservadoras ${ }^{\mathrm{ii}}$ nos faz voltar ao tempo em que a escola não conseguia abraçar o aluno e nem este tinha como abraçar a escola. E nessa viagem de volta ao tempo, nós educadores de hoje, revivemos a nossa própria história de estudantes sem voz e não é essa marca que queremos deixar na história de nossos alunos.

\begin{abstract}
Segundo Foucault (2011), a anormalidade se constitui por meio de discursos, processos e práticas que produzem o metro-padrão, a formatação da vida, a governabilidade, e, em decorrência, produzem os diferentes. Esses discursos, processos e práticas são conservadores e levam à regulamentação do normal e do metro-padrão, assim como estabelecem os critérios de normalização, como a cura, a adaptação, a correção e a modelação dos sujeitos fabricando concomitantemente os "anormais", ou seja, aqueles que fogem da forma e do padrão de normal. Assim, percebemos que esses discursos, processos e práticas se apresentam como conservadores e produzem efeitos de verdade, fabricando, dessa forma, as identidades almejadas e uniformizadas. Entendemos que o sentimento de anormalidade, muitas vezes, está presente entre alunos que sofrem processos de exclusão, o que interfere nos processos de produção das identidades dessxs estudantes. (SEPULVEDA \& SEPULVEDA, 2017, p.23).
\end{abstract}

Não ter tido voz enquanto estudante, fez-me vivenciar o vazio da negação de cada aluno. Hoje, é possível concluir que este silenciamento imposto por práticas educacionais mais conservadoras não contribuiu para uma sociedade mais justa.

Ter experimentado vivências educacionais onde foi possível ver a transformação da escola em um espaço de formação de indivíduos capazes de refletir sobre diferentes realidades e buscar alternativas para intervir, nos mostrou que é possível conviver e aceitar a diversidade, que é possível buscar parcerias, que assim o futuro pode ser melhor, que o aluno é alguém vivo e tem voz dentro do processo e que lutar não é guerrear nem odiar e sim, conquistar. Experiências positivas dentro de escolas abraçando políticas de ações afirmativas e projetos educacionais que buscassem abordar as diferentes realidades que fazem parte da diversidade dos muitos grupos dentro de um ambiente escolar, além de tornar o aluno protagonista de seu processo, conseguiram transpor os muros da escola, imprimiram novas marcas nos alunos e permitiram experimentar o mais inovador que a escola passou a propiciar: o prazer! Sim! Existe essa possibilidade! É possível aprender com prazer. O que não significa desrespeito a autoridade do professor, desrespeito as regras e nem balbúrdia ${ }^{\text {iii }}$

Nunca antes havia existido o prazer na escola onde apenas era imposto o medo como estratégia de manutenção da ordem estabelecida. A escola não sabia construir relações, explicar regras e normas, tinha 
receio de que o diálogo derrubasse a autoridade. A difusão do medo é uma característica de ação dos conservadores, assim como expansão do pânico moral.

Em nossa análise, conservadorismo é uma categoria histórica, ou seja, deriva de processos sociais através do tempo e das relações de poder. Conhecemos o conservadorismo a partir dos discursos e das práticas das pessoas. Este processo histórico gera certa regularidade de argumentos para situações análogas, o que nos permite observar o desenvolvimento de uma cultura conservadora. Dessa forma, não é possível se pensar em conservadorismo como uma categoria estática, tanto sociológica quanto antropologicamente. A história é marcada por disputas, em especial por aquilo que se vinculou chamar de "luta de classes". O conservadorismo é um elemento ideológico que constrói senso comum. Portanto, não é exclusivo de nenhuma classe social. Na disputa por poder que ocorre no campo da cultura, o conservadorismo é um importante elemento na construção dos interesses de classe e na própria consciência de classe. Em tal processo, não estão em disputa somente as condições materiais de sobrevivência, estão também as condições simbólicas, compostas por diversas argumentações de diferentes naturezas, o que torna o processo de conscientização mais lento. (SEPULVEDA \& SEPULVEDA, 2016, p. 88).

$\mathrm{O}$ medo cria monstros e fantasias que acabam dominando as pessoas. Na história grega, Fobos injetava o medo no coração dos inimigos como uma estratégia para deixar de ter oponentes. Já seu irmão Deimos, era capaz de implantar o pânico em tropas inteiras. Ainda de acordo com a mitologia grega, os dois irmãos representavam o medo da perda.

A implantação de um terror baseado na exemplificação de lacunas que ainda existem em nossa sociedade, pode ser intencionalmente inserido para justificar o retorno do poder em mãos conservadoras, criando então uma necessidade e uma alternativa para a salvação. Não faltam em nossa história, exemplos de líderes conservadores e populistas que se valeram do medo para conquistar o apoio popular.

Vemos atualmente a intencionalidade de setores dominantes na perpetuação do medo para não permitir o prazer. Estamos voltando a ser silenciados, engessados, sentados e amendrontados. Aqueles valores que a escola trabalhou para construir como solidariedade, empatia, justiça, direito, equidade e respeito, se tornaram uma ameaça a ideia conservadora de educação que não aceita conceber o sujeito além de um comportamento único, pré-estabelecido e esperado.

Trabalhar com música no contexto escolar enquanto projeto é uma ferramenta acessível de questionamento e reflexão que vai além da Educação Musical tradicional, proporcionando aos alunos a oportunidade de revelar seus gostos, escolhas, refletir sobre a subjetividade e valores transmitidos. E para isso, é preciso dar voz aos estudantes, é preciso permitir que exista um espaço onde os discursos se revelem, criem e recriem significados, onde os preconceitos apareçam, as diferenças fiquem evidentes e as intolerâncias questionadas para que possam ser desconstruídas. É preciso que o medo do que possa ser revelado não seja injetado por Fobos.

\section{Uma experiência pedagógica}


A escola não é um território somente de aprendizagens formais, mas também um espaço de interações sociais e construção de identidades, sendo assim, é possível compreender que a escola é um lugar de manifestação de diferentes culturas e é um rico espaço de instrumento de conscientização do cidadão, extrapolando sua função de mera transmissora de conhecimento e abraçando uma ação social diretamente relacionada à formação do senso crítico, sendo ponte para a intervenção e mudança da realidade social. Tocando o aluno no que realmente o afeta, como a música, no caso específico deste relato. A música está intimamente ligada ao universo da maioria das crianças e jovens, sendo, portanto, uma ponte de diálogo possível entre a proposta pedagógica e o estudante (seja qual for o estilo ou tendência, já que isto não é questão neste trabalho).

Se o problema é fazer com que a escola atenda aos interesses de seus alunos e suas alunas, se temos a intenção de construirmos uma escola de qualidade, preocupada em instrumentalizar as classes populares para que tenham meios de lutar contras as estruturas sociais que as oprimem, devemos pensar a questão do currículo sobre novas bases, tendo como princípio orientador o resgate das experiências pessoais, das histórias de vida, das culturas, das visões de mundo dos alunos e das alunas, a partir das relações que se dão no cotidiano da própria escola, para chegar ao mais longe possível, onde a curiosidade e a capacidade de busca de alunos, alunas, professoras e professores puderem levar. (TAVEIRA, 2000, p. 73).

Uma escola que fala, onde o aluno tem voz, é também uma escola que pensa. Uma escola que reflete criticamente é uma escola que busca mudanças. Silenciar a escola é levar o aluno de volta para a cadeira para apenas reproduzir.

Entendemos então, que esse medo de dar voz causa uma reação. Não podemos pensar sobre esse silenciamento apenas no campo das ideias, mas também em relação ao comportamento humano, porque quando se busca silenciar as vozes dos alunos, vemos pensamento e ação no confronto de valores envolvendo dança, sensualidade, sexualidade, concepções sobre a ideia dos gêneros, estereótipos, liberdade e muitas outras questões que se busca calar ao invés de questionar.

Esse silenciamento, às vezes é direto e às vezes disfarçado, isso ficou evidente durante uma proposta pedagógica com música desenvolvida em duas instituições (uma escola pública e uma privada), onde os alunos não puderam escolher, não puderam se envolver ou mesmo falar, cabendo a eles apenas a leitura e registro de respostas diante de perguntas diretas com o codinome de interpretação de texto. Ainda o fato de ter sido descartado por alguns professores, já que trata-se de uma proposta considerada extra ou desnecessária dentro do currículo escolar, não conseguindo entender que a transdisciplinariedade não é algo extra e sim a própria educação dando voz a convivência, a família, religiosidade, as relações, aos conflitos, aos valores e ao prazer.

No cotidiano da escola, no qual alunos(as) e professores(as) constroem suas relações, é que vão estar presentes as formas pelas quais estes sujeitos atribuem significado e substância ética às suas experiências de vida, é necessário reconhecer que estas relações 
trazem, em seu bojo, diferentes posicionamentos sociais e repertórios culturais diversos e se constituem em relações de poder. Um currículo democrático, interessado em resgatar as vozes desses sujeitos como elementos fundamentais do trabalho pedagógico, estará atento a esta diversidade e procurará explicitá-la, dela se utilizando para a problematização do conhecimento a ser criado e apreendido pelos alunos e pelas alunas, sem perder de vista a necessidade de assegurar a aquisição, por parte destes(as) estudantes, daqueles saberes valorizados socialmente. (TAVEIRA, 2000, p. 74).

Silenciar não foi apenas calar a voz, foi também impedir que novas vozes fossem produzidas, novas experiências fossem vividas e, tirar da escola e dos alunos novamente o prazer.

$\mathrm{Na}$ fala $^{\mathrm{iv}}$ de alguns educadores, podemos indentificar a escolha pelo distanciamento do aluno, assim como também revela a visão de mundo de cada um e um retorno ao tempo do silencio e do medo:

"É melhor usar apenas alguns trechos de músicas, algumas partes não pegam bem."

"Precisamos selecionar músicas com um conteúdo melhor, com valores morais, religiosos... Os alunos estão precisando ter mais valores morais e familiares."

"Tem música que não dá para tirar nada de bom."

"Imagina o tipo de música que vai surgir, se eles escolherem."

$\mathrm{E}$ as frases que ficaram muito marcadas:

"Não dá pra falar o que gosta, não estamos aqui pra isso, já chega de dar espaço aos alunos. Eles não estão em casa."

"Melhor deixar como era antes, obrigado."

O medo do prazer e o silenciamento criam sempre uma barreira e nunca uma ponte. Diante dessas falas, volto a refletir sobre as lacunas que ainda existem em nossa sociedade, dos casos de violência e desrespeito na escola que ainda não conseguimos solucionar em sua totalidade. Mas penso que o que ainda não conquistamos, é porque ainda precisamos lutar.

Marcamos os nossos alunos, seja com o silêncio ou com palavras, seja com o medo ou com a possibilidade de sorrir. Marcá-los com sonhos não é tirá-los da realidade, mas mostrar que um sonho construído, discutido, embasado e compartilhado, pode se tornar realidade.

É fundamental que o educador possa ser um espelho para os alunos, não para refletir ou copiar a própria imagem, mas para ser reflexo de uma postura respeitosa diante do mundo, de valores e saberes adquiridos, de possibilidades de escolhas, não as escolhas que agradem ao professor, mas as escolhas com as marcas do respeito e valorização da diversidade em um mundo plural. Marcas esssas, que ficam para a vida, como nos lembra Freire:

O professor autoritário, o professor licencioso, o professor competente, sério, o professor incompetente, irresponsável, o professor amoroso da vida e das gentes, o professor mal- 
amado, sempre com raiva do mundo e das pessoas, frio, burocrático, racionalista, nenhum desses passa pelos alunos sem deixar sua marca. (FREIRE, 2002, p. 73).

\section{Considerações finais}

É inegável a presença do pensamento e discurso conservador como um retrocesso na medida em que impede práticas de aulas com debates que possam ir além do previsto no conteúdo.

Precisamos nos dedicar a perceber os diversos aspectos e saberes que articulam as relações de poder na escola: o saber e o não saber, o gênero, a etnia, os interesses de classe. Estes estarão presentes, de forma explícita ou não, em todos os momentos e espaços que formam o cotidiano escolar. Desde o momento da entrada dos alunos e das alunas na escola, até o momento da merenda, a prova, a aula, o recreio, a sala, o pátio, o corredor, as interações dos alunos(as) e profissionais (professores(as), coordenadores(as), diretores(as), pessoal de apoio), de alunos(as) entre si, tudo enfim servirá de elemento para a produção de um currículo comprometido com uma educação de qualidade, que venha atender aos interesses de emancipação dos(as) estudantes dos grupos menos favorecidos. Como afirma Alves (1998, p. 127): O cotidiano está pleno de alternativas, pois construí-las é a sua própria forma de ser, de usar, de fazer. (TAVEIRA, 2000, p. 74).

Silenciar não impede a existência da realidade social e cultural vivida por nossos alunos, não evita a necessidade de desconstruir as intolerâncias, não resolve os preconceitos que ainda existem e que, infelizmente, parecem tender a aumentar.

Calar a voz não apaga a necessidade de falar.

\section{Referências}

FREIRE, Paulo. Pedagogia da Autonomia - Saberes Necessários à Prática Educativa. São Paulo: Paz e Terra, 2000.

FREIRE, Paulo. Pedagogia dos Sonhos Possíveis. São Paulo: UNESP, 2001.

GADOTTI, Moacir. A Educação Contra a Educação. Rio de Janeiro: Paz e Terra, 1992.

SEPULVEDA, Denize. Emancipação social e exclusão no cotidiano escolar: a homofobia e suas influências nas tessituras identitárias. Tese de Doutorado em Educação. Universidade do Estado do Rio de Janeiro: Rio de Janeiro, 2012.

SEPUlVEDA, Denize; SEPUlVEDA, José Antonio. Conservadorismo e educação ESCOLAR: um exemplo de exclusão. Movimento Revista de Educação. Ano 3, N. 5, 2016.

Práticas conservadoras: suas influências nas tessituras identitárias de gêneros e sexualidades. Periferia: educação, cultura e comunicação. V.9, N.2 jul-dez 2017.

TAVEIRA, Eleonora Barrêto. Saberes de alunos e alunas do ensino regular noturno: questão para a Escola? In: ALVES, Nilda: GARCIA, Regina Leite. A Invenção da Escola a cada dia. Rio de Janeiro: DP\&A, 2000. 


\section{Notas:}

${ }^{\text {i }}$ Professora, Pedagoga UERJ. Psicopedagoga PUC-Rio. Especialista em Educaçao Especial e Inclusiva (UFF). Educadora Social, Arte-educadora. Membro do Grupo de Estudo e Pesquisa os Impactos do Conservadorismo na Educação Brasileira (GEPCEB) da UFF.

ii Segundo Sepulveda \& Sepulveda (2017) vivenciamos na realidade política brasileira um período extremante conservador que vem influenciando a educação brasileira.

iii Balbúrdia foi a expressão usada pelo Ministro da Educação Abraham Weintraub ao dizer que as "Universidades que, em vez de procurar melhorar o desempenho acadêmico, estiverem fazendo balbúrdia, terão verbas reduzidas (O Estado de São Paulo (30 de abril de 2019). Disponível em https://educacao.estadao.com.br/noticias/geral,mec-cortara-verba-de-universidadepor-balburdia-e-ja-mira-unb-uff-e-ufba, 70002809579

iv Para diferenciar a fala dos educadores das citações teóricas as coloquei em itálico. 